\title{
How to build effective mentor-mentee relationships: Role of the mentee
}

\author{
Peter I. Tsai, MD, FACS, FCCP, ${ }^{a}$ and Bryan S. Helsel, MD ${ }^{b}$
}

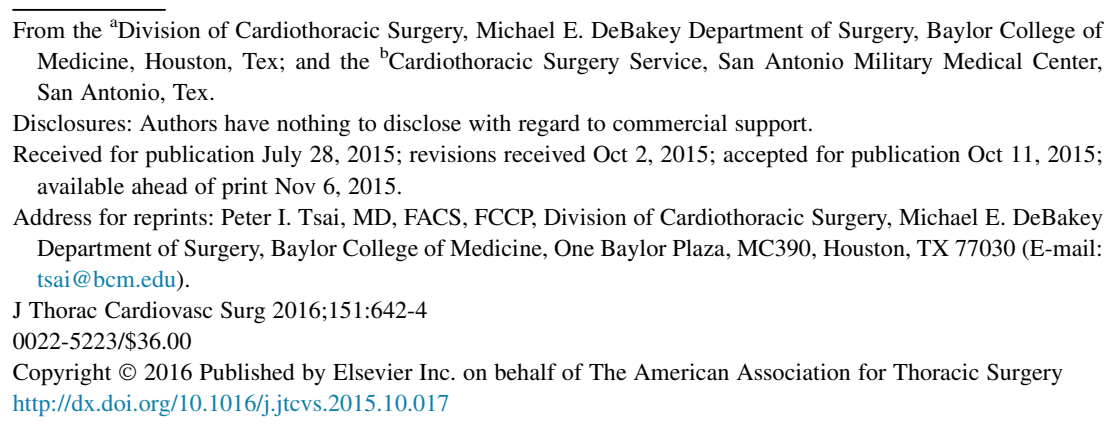

Much has been written on the subject of developing a mentor-mentee relationship, but almost exclusively from the mentor's perspective, as though it were a parental responsibility. A quick literature search on this subject confirms a lack of discussion by the mentees and their role in the relationship. This is unfortunate, because a good mentee should seek this relationship as he or she stands to benefit the most from it. We hope to add to the discussion from the mentee's perspective and spark more conversations to inspire mentees to seek these relationships actively.

Currently, we live in an era in which graduates of cardiac and thoracic track programs work with duty hour restrictions (80 hours) that lead to a waning of personal comfort with skillsets and experience in dealing with difficult, complicated, or challenging cases. On top of this, throw in the upsetting pass rate for both the qualifying and certifying examinations of the American Board of Thoracic Surgery in the recent years, and the resulting stress level compounds and can become overwhelming, adding to an already tumultuous journey to becoming a competent surgeon. If "mentored" by a more senior seasoned surgeon, however, the tide could turn.

First, we want to have a short discussion of some fundamentals in the mentor-mentee relationship. The role of mentor or mentee is somewhat arbitrary and evolving. This editorial is directed toward young surgeons who have completed their training and would like to know how to seek a mentor and be a good mentee. We must not forget, however, that we as young surgeons are also mentors simultaneously. We mentor surgeons in training at all levels, medical students, medical staff, and ordinary interested people who visit our operating rooms, clinics, and wards to see what we do. Unknowingly, some will become the next generation of cardiothoracic surgeons as a result of motivational experiences derived from their interactions with us. People will never consider what we do as a vocation unless they have these experiences. Circling back to our topic for this

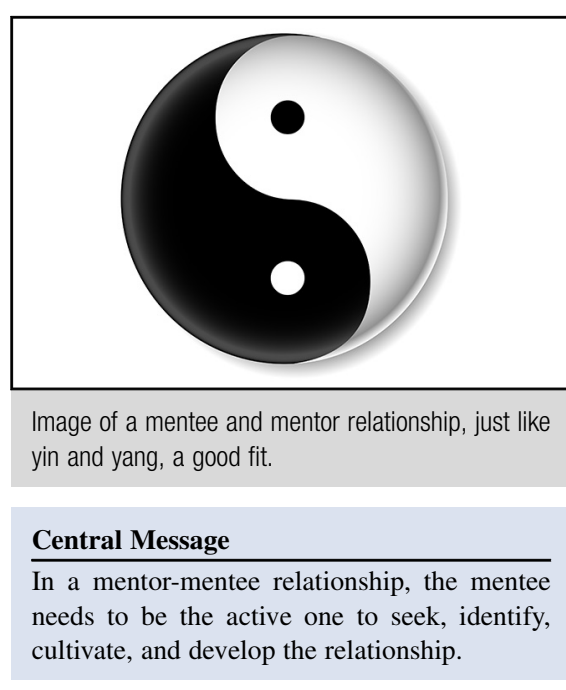

See Editorial Commentary page 645.

editorial, learning to be a good mentee certainly relates to being and becoming a good mentor. A good mentee who understands the role of mentors becomes a great mentor in the maturation process, and a few of us may become a perfect senior mentor-a "Jedi Knight" so to speak. This becomes a grassroots campaign in training and motivating mentees to develop great mentor-mentee relationships while consciously developing into resourceful mentors to others as well. The ripple effect continues and leads to mutual growth and collaboration, resulting in better practices, organizations, institutions, and true comradery, resulting in us becoming more consummate professionals and surgeons.

You have put in hard work through school to residency or fellowship and ultimately becoming a cardiothoracic surgeon. Don't stop now that you have finished training, because you certainly can't and shouldn't expect to be "spoon fed" from a senior partner or mentor in either an academic or private practice setting! We need to put equal thought, consideration, and "hard work" into engaging, seeking, maintaining, and nurturing effective relationships with our mentors. From the perspective of a mentee, the "perfect" mentor-someone you want to emulate, admire and develop into-is one who is confident, talented in clinical and technical skills, amicable in social settings, productive in academics, and, not to forget in this day and age, possessed of the financial and business savvy to sustain and grow a successful and productive practice. Above all, 
this mentor wants, craves, and desires actively to follow, push, and grow your career!

The mentor who encompasses all such traits is very rare and often does not exist. If you find such a mentor, congratulations-you have won the jackpot. This editorial would not be necessary, though, if this were an easy or simple process. Unfortunately, these relationships are becoming fewer and less significant. Our short careers have led us to the observations that most senior surgeons are not "perfect" mentors, and some are not even contemplating a mentor role; interestingly, however, all senior surgeons possess one or more of these valuable traits and are often willing to engage in this relationship if approached. The trick is simple-find one mentor who has all the traits desired, or find multiple mentors who will cover all the traits you want and engage in a meaningful and productive mentor-mentee relationship - maybe it will become the perfect one! It is also important to acknowledge that we may need different mentors with expertise at different stages or for different aspects of our career. We must also be wise to solicit new mentors with different strengths, such as research or administration, as the focus of our career changes as we become more senior in practice. The ball is in our court. We have to seek out these relationships and own them. We benefit from these relationships, so we must be devoted to maintaining them as well. As mentees, we should start off by thinking about where we would like to focus outside the operating room-teaching, research, administration, or practice development-and seek out specific mentors to target our interests. The following are traits, listed not particularly in order of importance, that we find useful.

\section{CLINICAL AND TECHNICAL SKILLS}

As a mentee, your work begins and builds from this search. In our specialty, these skills are absolutely necessary for a successful career. Vital, just like the cold surgeon's blade to cut into the "heart of the matter," is that of a mentor who is present and has the technical skills to assist, advise, and bail you out of trouble in challenging situations inside and outside the operating room, especially at the start of your journey. This help can come with case selection by helping you in choosing "relatively healthy," lower risk patients - to build your confidence in your technical skills and simultaneously develop the confidence of referring providers in you. Some of the most important guidance from a respected mentor is learning the judgment to determine which patients need an operation and when, but often more crucial is to determine which patients you should refuse an operation and how to politically navigate this decision among the referring providers. A mentor who is clinically and technically talented but who is also empathetic and compassionate in providing the best treatment is an ideal mentor in this arena but often rarely exists. Here again, it may take more than one mentor to help achieve all of these attributes you desire. A mentee must honestly reflect and critically assess his or her skills and then actively seek a mentor who has the skills necessary to help grow and maintain those skills. A mentor can be crucial in an honest assessment of your needs. Conversely, if a mentee is particularly strong and talented in technical skills, then the need for a mentor strong in this setting becomes less necessary.

\section{ACADEMICS}

Here we split this topic into research and publications and society participation.

\section{Research and Publications}

For those of us who are in academics, and even those who are in private practice but still wish to pursue research and publications, we should seek the help of a "big name" academic mentor. We should seek a mentor who is willing to give and share opportunities in research, writing, publications, and presentations but also is able to critically assess our thoughts and presentation of these thoughts in a constructive manner to inspire growth and maturity in our product. The mentor's experience in clinical or basic research and trials can complement as an advisor or senior collaborator. The mentee must actively seek and inquire about opportunities to write chapters and start research projects ranging from basic science to applying for and running major trials with National Institutes of Health grants. As mentees we must actively take classes or workshops outside our mentor relationship on research grant writing, teaching, and evaluation to provide the foundation for our mentors to assist us.

\section{Society Participation}

A mentor who is active in professional organizations is almost mandatory. Such a mentor will involve and introduce the mentee into formal academic or local societies and professional organizations to increase exposure of the mentee to others, including peers. This can start way before the mentee is finished with residency training. Active participation at an early stage as a resident member or by creating posters and making oral presentations is fruitful. Regular attendance at annual societal conferences and meetings provides the opportunity for making and maturing connections. If you are aggressive and do your part, then the mentor's job becomes easy, and often the mentor just provides introductions and background endorsements. These simple introductions, however, can lead to opportunities that ultimately result in significant appointments within these societies. The mentee must consciously and actively seek the aid of a mentor in these societies to determine areas and committees to apply and participate that best suit the mentee's goals and interest. The mentor 
is also crucial in the planning to achieve these goals. You must sit down with your mentor and determine your goals within these societies early in your relationship for your mentor to be most effective. Typical societal groups to join are American College of Surgeons, The American Association for Thoracic Surgery, The Society of Thoracic Surgeons, Society of University Surgeons, Association for Academic Surgery, Southern Thoracic Surgical Association, and Western Thoracic Surgical Association, to name a few. Don't forget, because we are cardiothoracic surgeons, we should also consider American College of Cardiology, American College of Chest Physicians, and American Heart Association. Of utmost importance is to realize that, regardless of our appointment positions in these professional organizations, our active membership and participation are critical to advancing our field as a whole.

\section{Additional Considerations}

As a special note to those who aspire to become professors in the academic setting: you need to start early, similar to achieving any monumental goal. Identify, in conjunction with your mentor, a time line that includes promotion goals from assistant to associate professor, preferably in the tenure track. Then, in accordance with your institution's guidelines, there are "awards" in education and teaching and in clinical productivity that you should consider as steps to attain along the promotion trail. Discuss your productivity with your mentor at least annually, gaining guidance on what papers to write, how many, at what meetings to present, and revisit these goals more frequently as needed. Remember, you as the mentee drive the ship-you can sail with the wind and let nature take its course or be a powerboat and drive for your goals at full speed-whatever "floats your boat!" The mentor serves as the GPS, steering you ever so gently toward your destination.

One achievement that is crucial, above and beyond all the others, is to pass your Boards. Believe it or not, it matters tremendously and shows your personal motivation to accomplish a task and reach a standard that marks you as a professional. You are not allowed to participate in many of the surgical societies without this certification, particularly to achieve the status of Fellow of the American College of Surgeons. There are numerous organizations and review courses to improve your chances of passing the tests and achieving certification. Use them, be very serious, work hard, and you will be rewarded-but this is up to you to make happen.

\section{BUSINESS SAVVY}

Be it in academics or private practice, the metric that administrators use to gauge your productivity is the relative value unit system-what they pay you and what you can generate must balance; otherwise, at the end of your initial contract, you might be unpleasantly surprised with a financial pay cut justified by your low volume and revenue generation for the years past. This is done by the school, the administration, or your own business or surgical partner! Know your contract. Seek the help of a mentor or a lawyer well versed in such matters and understand every part of your contract, because this is what you are going to be held accountable for when they review. You must be very serious about achieving the targeted financial goals, or you may become the target. Learn Current Procedural Terminology coding through courses and workshops offered, and master its application with the aid of your mentor. Often you are already doing the work, but you have to document it by coding well. The more savvy you are about finance, the more valuable you are to the organization. Some will seek out further education to include MBA degrees to gain further knowledge and credibility with peers and the organization in which they work. Again, it starts with the mentee, and actively seeking the aid and guidance of a mentor who understands the politics, business goals, and strategies of the organization in which you live.

\section{PERSONAL AND FAMILY LIFE}

In this day and age, we are proud to serve our country, our careers, and, equally, our families. Identify mentors who personally invest in their health and families. The trick here is to be aware of the positive and negative examples (what to avoid) that mentors can exhibit. You can determine this by direct observation and personal contact with mentors, their spouses, and their families. The mentee should emulate these mentors, and invest time in personal health, fitness, diet, and an intense focus on family needs and commitment. Communication is the key to family time and commitments-helping your spouse appreciate the time constraints and demands from your career, but also helping to understand that your ultimate desire is to provide and commit as a spouse and parent to your children. This certainly helps ease the family tension that often exists in our specialty. Don't forget, your children will only be there once. If you don't pay attention and spend time with them, you will look up and find that they are gone forever.

The recurring theme is clear-it is the mentee, us, who drives the ship. Having the resource of an All-Star Mentor is a luxury, and often we need many mentors to determine and achieve our goals. You might hit the jackpot, but know that it's rare. These relationships often start informally, but will grow and mature with time when focused attention is given. However, we have to get started, get involved, and make this a priority! Otherwise, it never happens. As we become better mentees, we are also becoming better mentors. This is an evolution, because as we seek to be good mentees to achieve our goals we find that we are also mentors to others. Start with what you can do. Be a great mentee. Happy trails. 